\title{
Tumor Results Reason Not Done
}

National Cancer Institute

\section{Source}

National Cancer Institute. Tumor Results Reason Not Done. NCI Thesaurus. Code C117418.

The rationale why a tumor measurement was not performed. 